\title{
Relative roles of insulin and hypoglycaemia on induction of neuroendocrine responses to, symptoms of, and deterioration of cognitive function in hypoglycaemia in male and female humans
}

\author{
C. Fanelli ${ }^{1}$, S.Pampanelli ${ }^{1}$, L. Epifano ${ }^{1}$, A.M. Rambotti ${ }^{1}$, M. Ciofetta ${ }^{1}$,F.Modarelli ${ }^{1}$, A.Di Vincenzo ${ }^{1}$, \\ B. Annibale ${ }^{2}$, M. Lepore ${ }^{1}$, C. Lalli ${ }^{1}$, P.Del Sindaco ${ }^{1}$, P. Brunetti ${ }^{1}$, G. B. Bolli ${ }^{1}$ \\ ${ }^{1}$ Dipartimento di Medicina Interna e Scienze Endocrine e Metaboliche, Università di Perugia, Perugia, Italy \\ ${ }^{2}$ Cattedra di Gastroenterologia, II Clinica Medica, Università "La Sapienza", Rome, Italy
}

\begin{abstract}
Summary To assess the relative roles of insulin and hypoglycaemia on induction of neuroendocrine responses, symptoms and deterioration of cognitive function (12 cognitive tests) during progressive decreases in plasma glucose, and to quantitate glycaemic thresholds, 22 normal, non-diabetic subjects (11 males, 11 females) were studied on four occasions: prolonged fast ( $n=8$, saline euglycaemia study, SA-EU), stepped hypoglycaemia (plasma glucose plateaus of $4.3,3.7,3$ and $2.3 \mathrm{mmol} / \mathrm{l}$ ) or euglycaemia during insulin infusion at 1 and $2 \mathrm{mU} \cdot \mathrm{kg}^{-1} \cdot \mathrm{min}^{-1}(n=22$, high-insulin hypoglycaemia and euglycaemia studies, HI-INS-HYPO and HI-INS-EU, respectively), and stepped hypoglycaemia during infusion of insulin at $0.35 \mathrm{mU}$. $\mathrm{kg}^{-1} \cdot \min ^{-1}$ ( $n=9$, low-insulin hypoglycaemia study, LO-INS-HYPO). Insulin per se (SA-EU vs HI-INSEU), suppressed plasma glucagon $(\sim 20 \%)$ and pancreatic polypeptide $(\sim 30 \%)$, whereas it increased plasma noradrenaline $(\sim 10 \%, p<0.05)$. Hypoglycaemia per se (HI-INS-HYPO vs HI-INS-EU) induced responses of counterregulatory hormones (CRHORM), symptoms and deteriorated cognitive function. With the exception of suppression of endogenous insulin secretion, which had the lowest glycaemic threshold of $4.44 \pm 0.06 \mathrm{mmol} / \mathrm{l}$, pancreatic polypeptide, glucagon, growth hormone, adrenaline and cortisol had similar glycaemic thresholds $(\sim 3.8-3.6 \mathrm{mmol} / \mathrm{l})$;
\end{abstract}

noradrenaline $(3.1 \pm 0.0 \mathrm{mmol} / \mathrm{l})$, autonomic $(3.05 \pm$ $0.06 \mathrm{mmol} / \mathrm{l})$ and neuroglycopenic $(3.05 \pm 0.05$ $\mathrm{mmol} / \mathrm{l})$ symptoms had higher thresholds. All 12 tests of cognitive function deteriorated at a glycaemic threshold of $2.45 \pm 0.06 \mathrm{mmol} / 1$, but 7 out of 12 tests were already abnormal at a glycaemic threshold of $2.89 \pm 0.06 \mathrm{mmol} / \mathrm{l}$. Although all CR-HORM had a similar glycaemic threshold, the lag time of response (the time required for a given parameter to increase) of glucagon $(15 \pm 1 \mathrm{~min})$ and growth hormone $(14 \pm 3 \mathrm{~min})$ was shorter than adrenaline $(19 \pm 3 \mathrm{~min})$ and cortisol $(39 \pm 4 \mathrm{~min})(p<0.05)$. With the exception of glucagon (which was suppressed) and noradrenaline (which was stimulated), insulin per se (HI-INSHYPO vs LO-INS-HYPO) did not affect the responses of CR-HORM, and did not influence the symptoms or the cognitve function during hypoglycaemia. Despite lower responses of glucagon, adrenaline and growth hormone (but not thresholds) in females than males, females were less insulin sensitive than males during stepped hypoglycaemia. [Diabetologia (1994) 37: 797-807]

Key words Hypoglycaemia, counterregulatory hormones, symptoms, cognitive function, sympathetic nervous system, glycaemic thresholds, pancreatic polypeptide, gender.
Received: 11 January 1994

and in revised form: 18 March 1994

Corresponding author: Professor G.B.Bolli, Istituto di Medicina Interna e Scienze, Endocrine e Metaboliche, Via E.Dal Pozzo, I-06126 Perugia, Italy
It is well established that normal humans respond to an acute decrease in plasma glucose concentration, first, by suppressing endogenous insulin secretion, and, second, by increasing counterregulatory hormones. These responses occur following a plasma glucose decrement of only $\sim 1 \mathrm{mmol} / \mathrm{l}$ below the values of the post-absorptive state. The third response is the appearance of hypoglycaemic symptoms, which only occur if the plasma 
glucose concentration decreases further $(\sim 1.8 \mathrm{mmol} / \mathrm{l})$. Finally, with larger decreases in plasma glucose concentrations, brain function becomes impaired [1-4].

The hypoglycaemic clamp technique has been used to quantitate the glycaemic thresholds for release of counterregulatory hormones, appearance of symptoms and onset of cognitive dysfunction [1-6]. There is quite a good agreement among studies, regarding glycaemic thresholds for release of the counterregulatory hormones glucagon, adrenaline and growth hormone [16]. However, several aspects of physiological responses to hypoglycaemia are either controversial or have not been investigated.

For example, different glycaemic thresholds for responses of plasma noradrenaline and cortisol have been reported in different studies [1-3, 6]. In addition, it is controversial as to whether the glycaemic threshold for appearance of autonomic symptoms is lower than that of neuroglycopenic symptoms (i.e. a smaller decrease in plasma glucose concentration is sufficient to elicit the autonomic as compared to neuroglycopenic symptoms) [2, 3, 6]. Furthermore, the glycaemic thresholds of suppression of endogenous insulin secretion and increase in pancreatic polypeptide in response to insulin-induced hypoglycaemia have not been studied. In addition, insulin appears to be involved in the responses of some counterregulatory hormones [7-10] and appearance of symptoms [11]. However, the contribution of insulin, independent of hypoglycaemia, on glycaemic thresholds and magnitude of responses of counterregulatory hormones, symptoms and deterioration of cognitive function, is unclear. Finally, it has been proposed that gender influences the physiological responses to hypoglycaemia [12-15].

The present series of studies were undertaken to assess, first, the relative roles of insulin, hypoglycaemia and gender on induction of neuroendocrine responses, symptoms and deterioration of cognitive function during progressive decrease in blood glucose, and second, to quantitate the glycaemic thresholds of these responses.

\section{Subjects and methods}

Subjects. Institutional Review Board approval was obtained for these studies. Informed consent was given by 22 (11 males, 11 females) healthy, non-obese (body mass index, BMI, $22.3 \pm 0.6 \mathrm{~kg} / \mathrm{m}^{2}$ ) volunteers aged $31 \pm 3$ years. Male and female subject groups did not differ regarding age and BMI. The subjects were studied on three different occasions, separated by at least 10-14 days. All 22 subjects participated in the first two studies in which insulin was infused at a high rate (high-insulin euglycaemia and high-insulin hypoglycaemia studies, respectively). Eight subjects (four male, four female) participated in a third study which consisted of a prolonged fast (saline euglycaemia). Nine subjects (five males, four females) participated in a third study in which hypoglycaemia was induced by a low dose of insulin (low-insulin hypoglycaemia).
Study design. Subjects were admitted to the Clinical Research Center of the Dipartimento di Medicina Interna e Scienze Endocrine e Metaboliche, University of Perugia, the morning of the studies between 07.00 and 07.30 hours after a 12-h overnight fast. They were put to bed and maintained in the supine position throughout the experiments. An 18-gauge catheter needle was inserted into a superficial vein of a forearm for infusion of $0.9 \%$ $\mathrm{NaCl}$, insulin and glucose. A 19-gauge butterfly needle was inserted retrogradely into a dorsal vein of the contralateral hand, with the hand maintained in a plexiglass thermoregulated box $\left(65^{\circ} \mathrm{C}\right)$ for sampling of arterialized-venous blood [16]. Both forearm and hand venous lines were kept patent by infusion of $0.9 \% \mathrm{NaCl}, 0.5 \mathrm{ml} / \mathrm{min}$, by means of two separate peristaltic pumps (VM $8000 \mathrm{M}$, Vial Medical, St-Martin-Le-Vinoux, Grenoble, France). In all studies, the time "zero" was 09.00 hours. In all studies the subjects remained on a fast, and were studied according to the following four designs.

Saline euglycaemia. Subjects $(n=8)$ were monitored for $360 \mathrm{~min}$ while receiving only i.v. $0.9 \% \mathrm{NaCl}$. These studies were performed first in order to define the plasma glucose concentration to be reproduced in the subsequent studies.

High-insulin euglycaemia and high-insulin hypoglycaemia. Subjects $(n=22)$ received a continuous intravenous infusion of regular insulin (Actrapid HM $40 \mathrm{U} / \mathrm{ml}$, Novo Nordisk, Denmark, diluted to $1 \mathrm{U} / \mathrm{ml}$ in $2 \mathrm{ml}$ of the subject's whole blood and $0.9 \% \mathrm{NaCl}$ to a final volume of $100 \mathrm{ml}$ ), by means of a syringe pump (Harvard, South Ealing, Mass., USA) at a rate of 1 $\mathrm{mU} \cdot \mathrm{kg}^{-1} \cdot \mathrm{min}^{-1}$ for $270 \mathrm{~min}$, followed by $2 \mathrm{mU} \cdot \mathrm{kg}^{-1} \cdot \mathrm{min}^{-1}$ for an additional $90 \mathrm{~min}$ to reach the lowest hypoglycaemic plateau (see below). Subjects were studied on two occasions. On the first occasion, plasma glucose concentration was maintained at the euglycaemic levels observed in the previous saline euglycaemia studies by means of the glucose clamp technique [17], as previously reported [18] (high-insulin euglycaemia). On the other occasion, plasma glucose was clamped by variable glucose infusion at sequential target concentrations of $4.3,3.7,3,2.3 \mathrm{mmol} / \mathrm{l}$, as previously described [1-3]. Plasma glucose concentration was allowed to decrease by about, $0.6-0.7 \mathrm{mmol} / \mathrm{l}$ over $30-45 \mathrm{~min}$, and a plateau was maintained for $45 \mathrm{~min}$ before the next decrease. The sequence of high-insulin euglycaemia and high-insulin hypoglycaemia studies was varied at random.

Low-insulin hypoglycaemia. Insulin was infused at a rate of 0.35 $\mathrm{mU} \cdot \mathrm{kg}^{-1} \cdot \mathrm{min}^{-1}$ in nine subjects, and plasma glucose was clamped by variable glucose infusion at sequential target concentrations of $4.3,3.7$, and $3 \mathrm{mmol} / \mathrm{l}$. Because of the relatively low rate of insulin infusion in these studies it was not possible to decrease the plasma glucose concentration below $3 \mathrm{mmol} / \mathrm{l}$.

Arterialized-venous blood samples were drawn every $30 \mathrm{~min}$ (every $15 \mathrm{~min}$ in the high-insulin euglycaemia and high-insulin hypoglycaemia studies) from -30 to $360 \mathrm{~min}$ for determination of glucoregulatory hormones and pancreatic polypeptide. A semiquantitative symptom questionnaire was compiled every 15 min. Subjects scored from 0 (none) to 5 (severe) for each of the following symptoms: dizziness, tingling, blurred vision, difficulty in thinking, faintness, anxiety, palpitations, hunger, sweating, irritability, and tremor. In accordance with previous classifications $[1-3,19]$, the first five symptoms were considered neuroglycopenic and the last six, autonomic. The sum of each of these constituted the symptom score. In addition, at baseline and during the last part of each plateau (60-90 min of each glycaemic step), the following standard cognitive tests were compiled: Trail-making part B, verbal fluency, interference subtest from the Stroop test, simple and choice visual reaction time, word and colour subtest from the Stroop test, digit vigilance test, trailmaking part $\mathrm{A}$, verbal memory test and forward and backward 


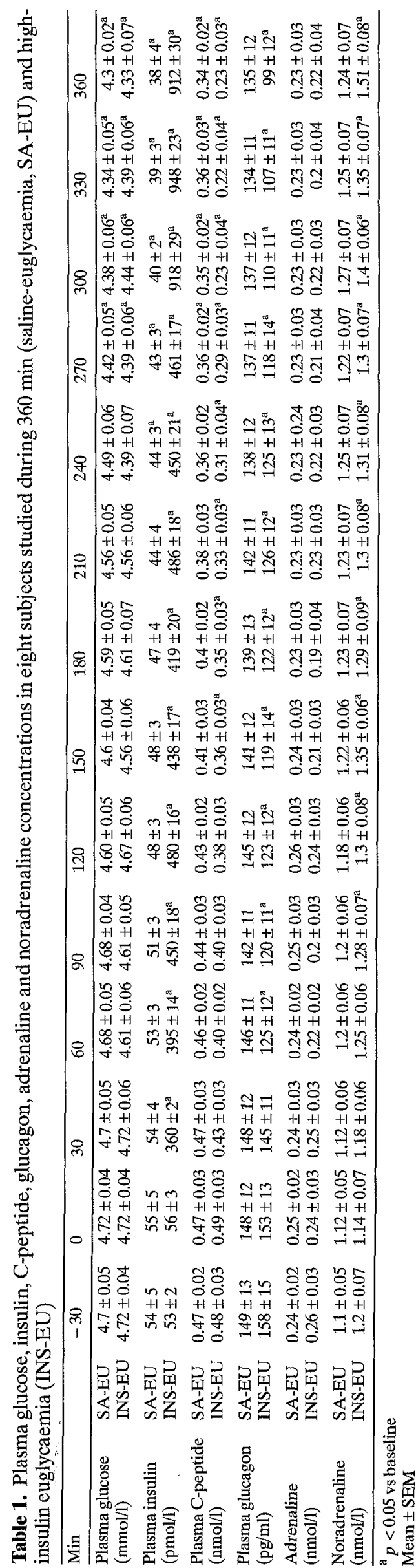

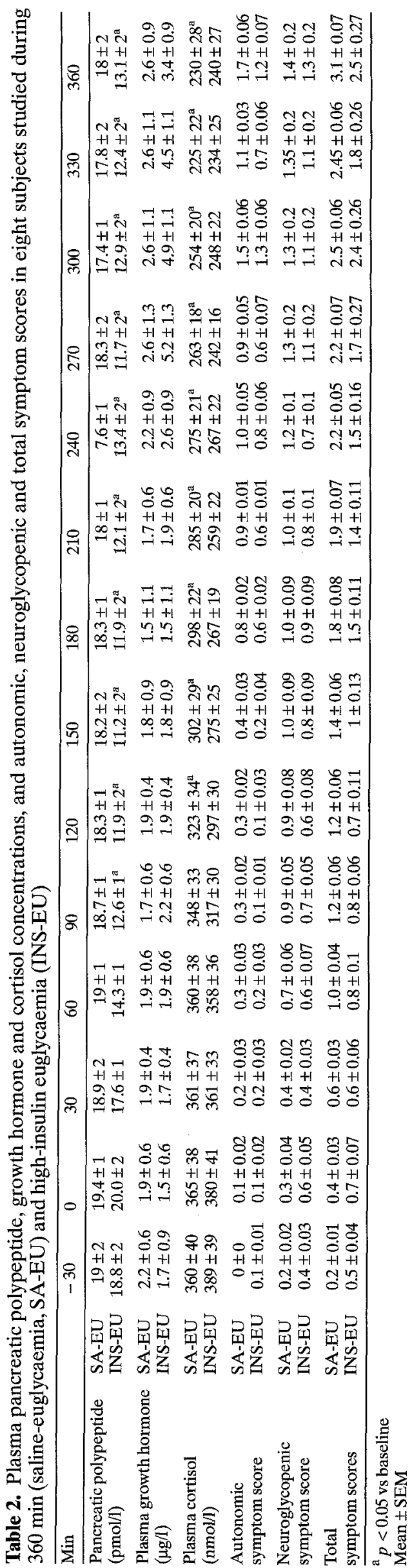


digit span, as previously described [3]. The evening before the study, subjects extensively practiced each test. For the actual study, six alternate forms were prepared. Subjects were not informed of their plasma glucose and insulin level during experiments.

Analytical methods. Plasma glucose was measured using a Beckman Glucose Analyzer (Beckman Instruments, Palo Alto, Calif., USA). Plasma insulin, C-peptide, growth hormone, cortisol, adrenaline and noradrenaline [20] and pancreatic polypeptide [21] were measured by previously described assays. Plasma glucagon was measured by radioimmunoassay using a commercially available kit (ICN, Biomedical, Inc., Costa Mesa, Calif., USA).

\section{Statistical analysis}

Glycaemic thresholds for a given parameter were defined as the plasma glucose concentration at which the parameter first exceeded the $95 \%$ confidence limit observed for changes in that parameter at the corresponding time point in euglycaemic control experiments. Lag time of response for a given parameter was calculated as time taken for each parameter to increase (as compared to euglycaemic experiments) once the glycaemic threshold of response had been reached. Data are given as means \pm SEM. Because of differences in units of measurements, results of cognitive tests were transformed to $z$ scores (for each, the individual value minus the mean value, divided by the standard deviation of the group mean) [22] to permit their summation to obtain one unitless value for evaluation [3], and expressed as percent change from baseline. A commercially available software package (CSS, Stasoft, Tulsa, O.K., USA) was used for statistical analysis. The differences among the groups were analysed by using either analysis of variance followed by the Least Significant Different test or the Chi-square test [22].

\section{Results}

\section{Effect of insulin on neuroendocrine responses,} symptoms and cognitive function in euglycaemia (saline euglycaemia vs high-insulin euglycaemia studies, Tables 1 and 2).

When subjects were monitored during a 360-min fast (saline euglycaemia), plasma glucose, insulin and Cpeptide concentrations decreased progressively. Plasma glucagon, adrenaline, noradrenaline, pancreatic polypeptide and growth hormone concentrations did not change, whereas plasma cortisol decreased (Tables 1 and 2). There was a slight, but non-significant increase in the symptom score (Table 2).

When subjects were infused with insulin and glucose to maintain euglycaemia (high-insulin euglycaemia studies), plasma insulin concentration increased to plateau values of $\sim 445 \mathrm{pmol} / 1(0-270 \mathrm{~min})$, and to $\sim 925 \mathrm{pmol} / 1$ (300-360 min), plasma C-peptide was suppressed by $\sim 25 \%$ and plasma glucagon concentration decreased by $\sim 13 \%$ between $30-270 \mathrm{~min}$, and by $\sim 23 \%$ between 300-360 min. Plasma adrenaline did not change; plasma noradrenaline increased by $~ 7 \%$
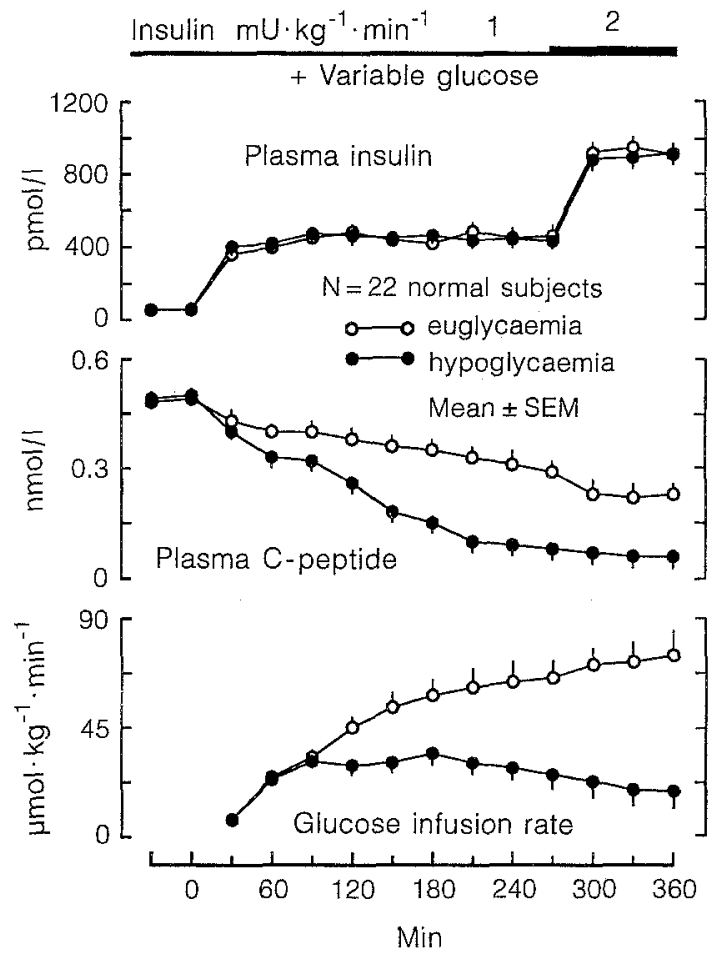

Fig. 1. Plasma insulin and C-peptide concentrations, and rates of glucose infusion required to maintain euglycaemia, or produce stepped hypoglycaemia during insulin infusion
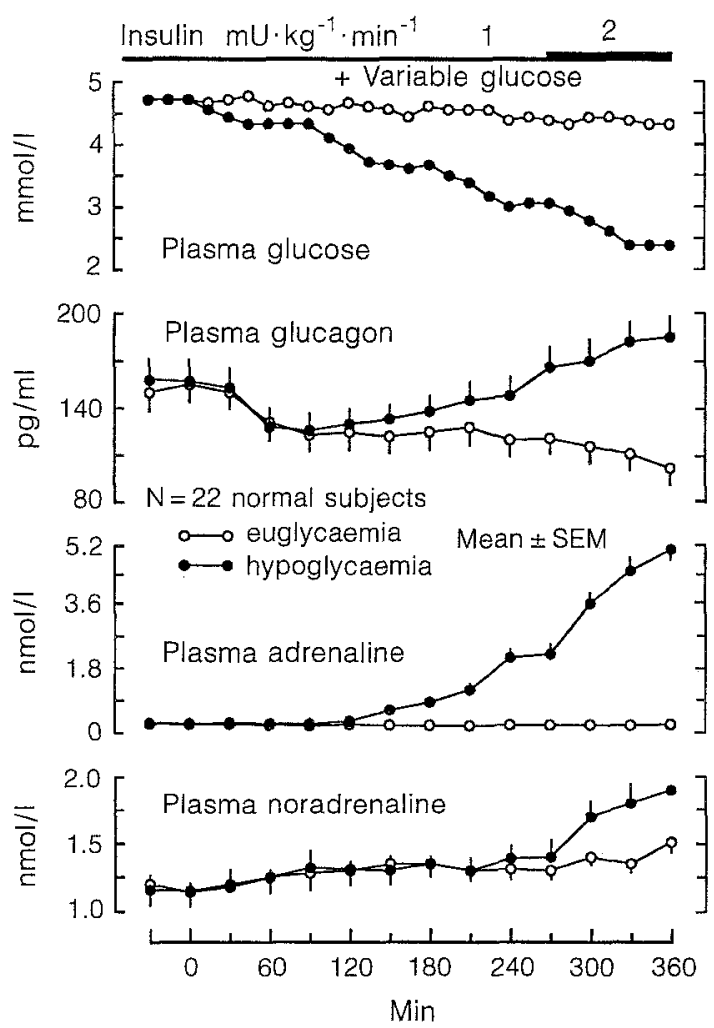

Fig. 2. Plasma glucagon, adrenaline and noradrenaline concentrations in response to either euglycaemia, or stepped hypoglycaemia (upper panel, plasma glucose), during combined insulin and glucose infusion 

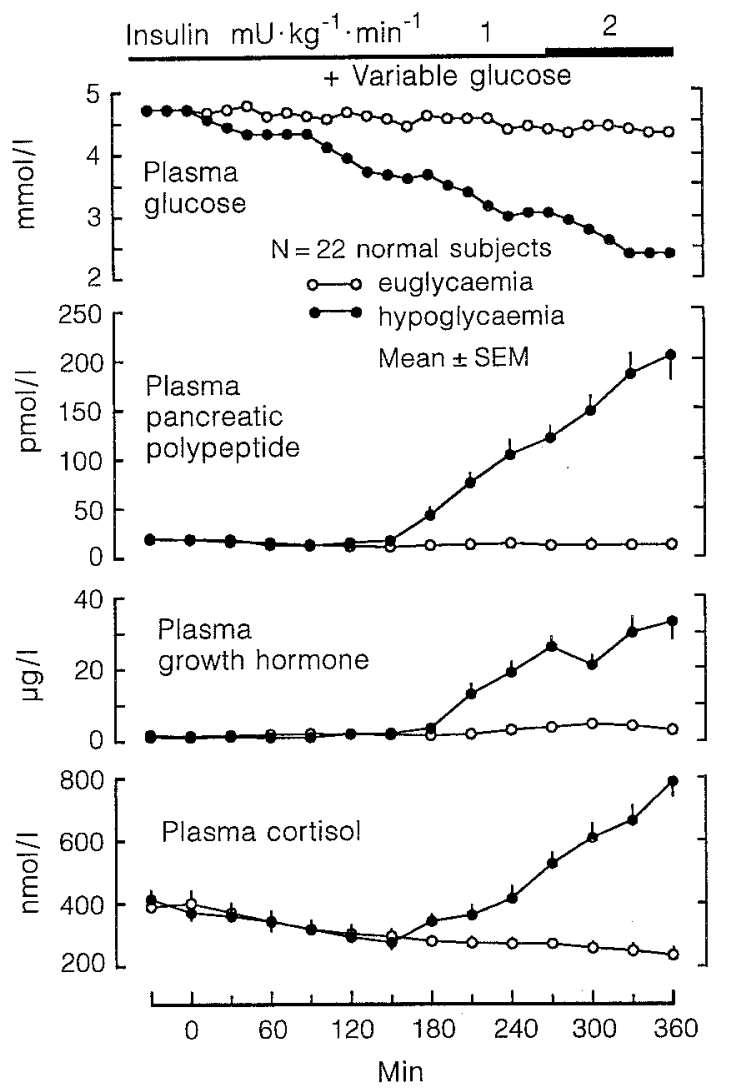

Fig. 3. Plasma pancreatic polypeptide, growth hormone and cortisol concentrations in response to either euglycaemia or stepped hypoglycaemia (upper panel, plasma glucose), during combined insulin and glucose infusion

between $90-270 \mathrm{~min}$, and by $\sim 14 \%$ between 300 $360 \min (p<0.05)$ (Table 1$)$. Plasma polypeptide concentration was suppressed by $\sim 30 \%$ between 90 $360 \mathrm{~min}$, growth hormone increased slightly, but not significantly after $270 \mathrm{~min}$, cortisol decreased throughout. Autonomic, neuroglycopenic and total symptoms increased slightly, but not significantly.

\section{Effects of hypoglycaemia on neuroendocrine responses, symptoms and cognitive function (high-insulin hypoglycaemia vs high-insulin euglycaemia studies)}

Plasma insulin and C-peptide concentrations, and glucose infusion rates (Fig. 1). Following insulin infusion, plasma insulin concentrations increased to similar plateau values in both the high-insulin euglycaemia and high-insulin hypoglycaemia studies. Plasma C-peptide decreased more in the hypoglycaemia than the euglycaemia study $(p<0.05)$. The amount of glucose infused in the euglycaemia study was greater than that throughout the hypoglycaemia study after $90 \mathrm{~min}$.

Plasmaglucose, glucagon, adrenaline and noradrenaline concentrations (Fig. 2). In the high-insulin euglycaemia studies, plasma glucose concentration was maintained
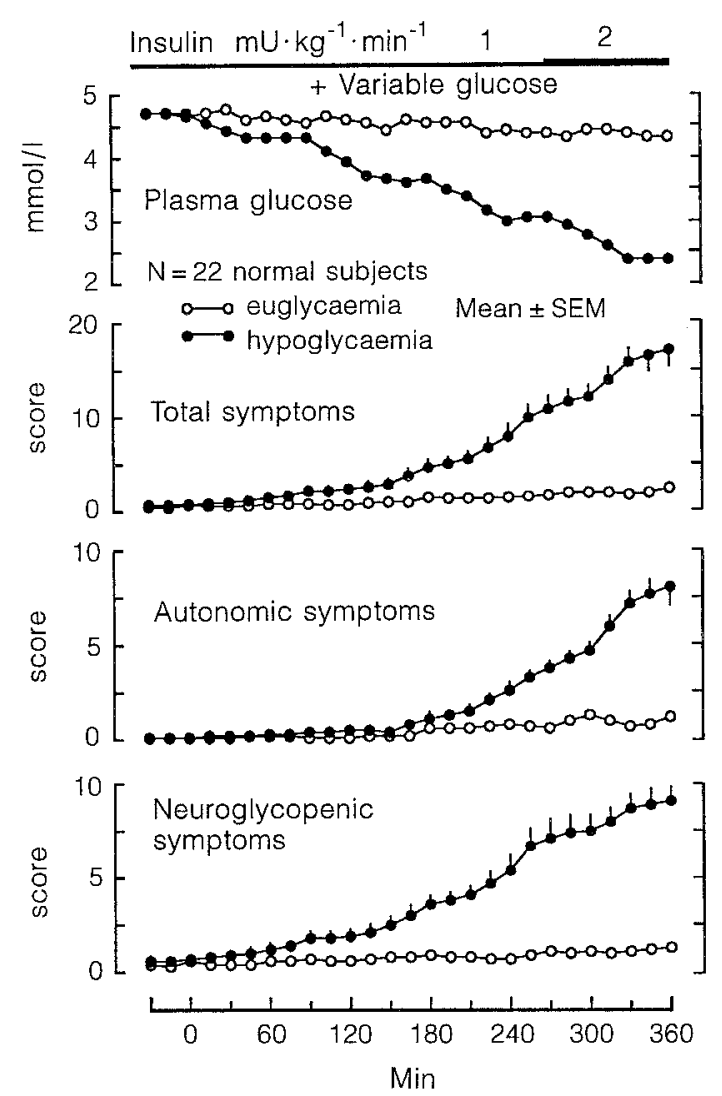

Fig.4. Symptom scores (total, autonomic, and neuroglycopenic) in response to either euglycaemia or stepped hypoglycaemia (upper panel, plasma glucose), during combined insulin and glucose infusion.

superimposable to the values of the saline euglycaemia study.In the high-insulin hypoglycaemia studies, plasma glucose concentration was decreased to plateaus of $4.3 \pm 0.02,3.6 \pm 0.02,3 \pm 0.02$, and $2.4 \pm 0.02 \mathrm{mmol} / 1$, between 45-90, 135-180, 225-270, and 315-360 min, respectively. In the high-insulin hypoglycaemia studies, afterinitialsuppression, plasma glucagon increased progressively after $120 \mathrm{~min}$ to a peak of $185 \pm 14 \mathrm{pg} / \mathrm{ml}$ at $360 \mathrm{~min}$; plasma adrenaline concentration increased after $150 \mathrm{~min}$ to a peak of $5.1 \pm 0.3 \mathrm{nmol} / 1$ at $360 \mathrm{~min}$; noradrenaline increased only after $300 \mathrm{~min}$.

Plasma pancreatic polypeptide, growth hormone and cortisol concentrations (Fig. 3). In the high-insulin hypoglycaemia studies, pancreatic polypeptide, after initial suppression, increased at $150 \mathrm{~min}$ and reached a peak of $206 \pm 24 \mathrm{pmol} / \mathrm{l}$ at $360 \mathrm{~min}$; growth hormone increased after $150 \mathrm{~min}$ to a peak of $32.9 \pm 4.9 \mu \mathrm{g} / \mathrm{l}$ at $360 \mathrm{~min}$; cortisol increased after $150 \mathrm{~min}$ to a peak of $786 \pm 56 \mathrm{nmol} / 1$ at $360 \mathrm{~min}$.

Total, autonomic, and neuroglycopenic symptoms (Fig. 4). The neuroglycopenic symptom score increased after $180 \mathrm{~min}$ to a peak of $9.2 \pm 0.9$ at $360 \mathrm{~min}$, and the autonomic symptom score increased after $210 \mathrm{~min}$ to a peak of $8.3 \pm 1.1$ at $360 \mathrm{~min}$. 


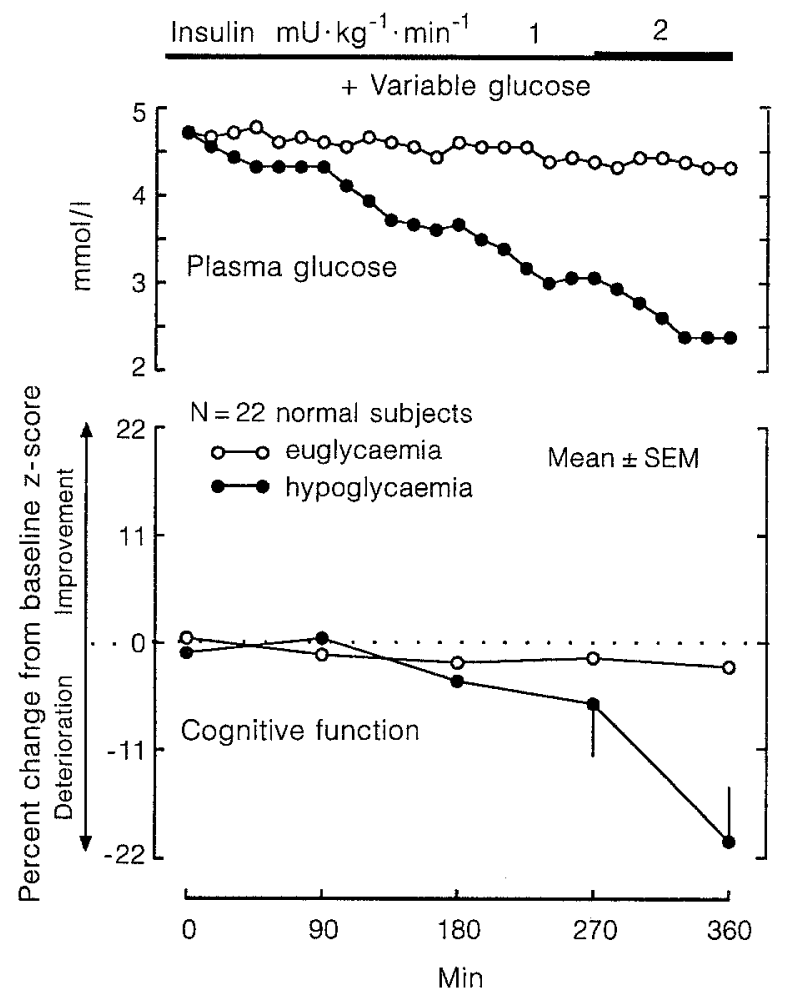

Fig.5. Cognitive function in response to either euglycaemia or stepped hypoglycaemia (upper panel, plasma glucose) during combined insulin and glucose infusion. Deterioration in cognitive function is represented as decrease in the percentage of sum of z scores of psychomotor tests (see "method" section) from baseline

Cognitive tests (Fig. 5). In the high-insulin euglycaemia studies, the sum of $z$ scores did not change over time. In contrast, in the high-insulin hypoglycaemia studies, the percentage change from baseline of the sum of $\mathrm{z}$ scores increased by $6.0 \pm 5.2 \%(p<0.05)$ for 7 out of the 12 psychomotor tests (Trail making part B, verbal fluency, simple and choice visual reaction time, word and colour subtest from the Stroop test, trail making part A), between 240 and $270 \mathrm{~min}$. All 12 psychomotor tests deteriorated between 330 and $360 \mathrm{~min}$, as indicated by the increase in the percentage of the sum of the $\mathrm{z}$ scores of $20.6 \pm 5.0 \%(p<0.05)$.

Glycaemic thresholds and activation times for neuroendocrine responses, symptoms and deterioration of cognitive function (Table 3). Among the glucoregulatory hormones, pancreatic endogenous insulin secretion (as reflected by plasma C-peptide) exhibited the lowest glycaemic threshold and the shortest time of activation. The counterregulatory hormones, glucagon, adrenaline, cortisol and growth hormone all had similar glycaemic thresholds, but the lag time of responses of cortisol and adrenaline were greater than those of growth hormone and glucagon $(p<0.05)$. The threshold of pancreatic polypeptide was no different from

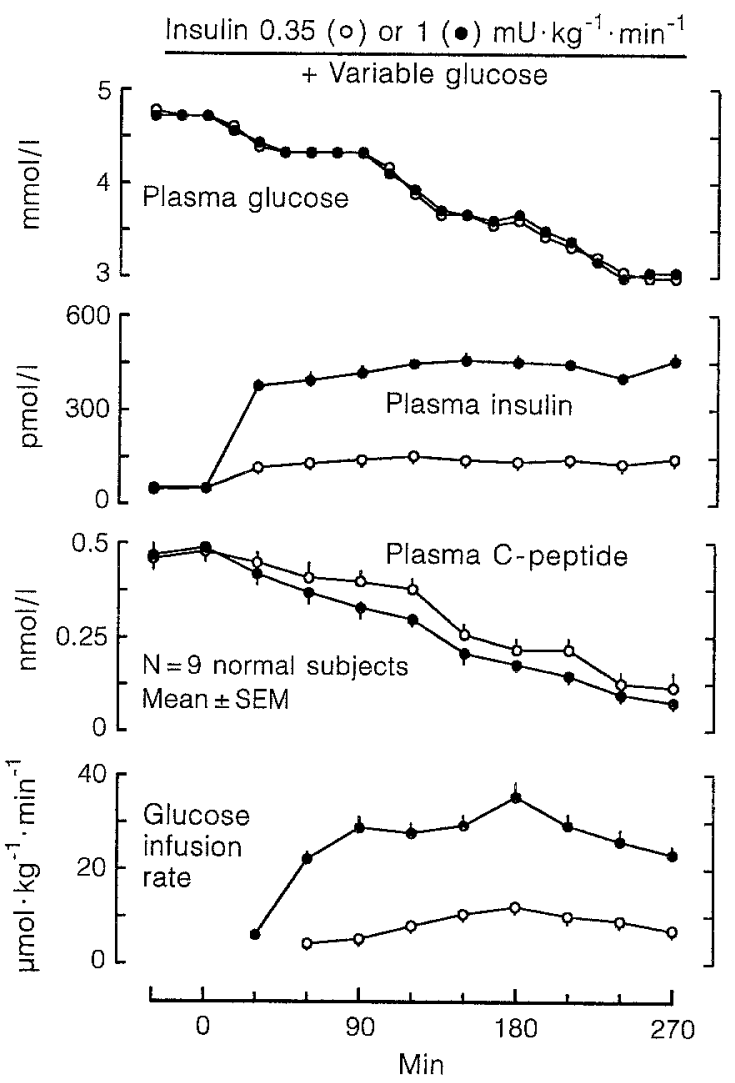

Fig.6. Plasma glucose, insulin and C-peptide concentrations, and rates of glucose infusion required to produce stepped hypoglycaemia during infusion of insulin at low and high rates in normal, non-diabetic volunteers

that of the counterregulatory hormones. The glycaemic thresholds of neuroglycopenic and autonomic symptoms were similar ( $p=\mathrm{NS}$ ). Plasma noradrenaline had the same glycaemic threshold as autonomic symptoms, but greater lag activation time. Deterioration of cognitive function was already evident at a glycaemic threshold of $2.89 \pm 0.06 \mathrm{mmol} / \mathrm{l}$ for 7 out of 12 psychomotor tests, whereas all 12 tests deteriorated at a glycaemic threshold of $2.45 \pm 0.06 \mathrm{mmol} / \mathrm{l}$.

Effect of gender (Table 4). Plateau plasma glucose, insulin and C-peptide concentrations in males and females were superimposable. Baseline and hypoglycaemia-stimulated plasma adrenaline concentrations were lower in females than males. Also plasma glucagon and growth hormone responses to hypoglycaemia were lower in females than in males (Table 4), whereas glycaemic thresholds were no different. In contrast, the responses of noradrenaline, pancreatic polypeptide and cortisol in females and males were no different ( $p=\mathrm{NS}$, data not shown). Despite lower counterregulatory hormone responses, the amount of glucose needed to maintain a hypoglycaemic plateau was lower in females than males (Table 4). In addition, despite lower adrenaline responses, the score of au- 
Table 3. Glycaemic thresholds and corresponding plasma glucose decrease from baseline, and lag time of response of counterregulation, initiation of symptoms and onset of deterioration of brain function

\begin{tabular}{lllc}
\hline & $\begin{array}{l}\text { Glycaemic } \\
\text { threshold }\end{array}$ & $\begin{array}{l}\text { Plasma glucose decrease } \\
\text { from baseline of 4.72 } 0.06 \\
(\mathrm{mmol} / \mathrm{l})\end{array}$ & $\begin{array}{l}\text { Lag time of } \\
\text { response } \\
(\mathrm{min})\end{array}$ \\
\hline C-Peptide & $4.44 \pm 0.06^{\mathrm{a}}$ & $0.28 \pm 0.02^{\mathrm{a}}$ & $0 \pm 0$ \\
Pancreatic polypeptide & $3.83 \pm 0.06$ & $0.89 \pm 0.03$ & $15 \pm 2$ \\
Glucagon & $3.72 \pm 0.06$ & $1.00 \pm 0.02$ & $15 \pm 1$ \\
Growth hormone & $3.66 \pm 0.06$ & $1.06 \pm 0.04$ & $14 \pm 3$ \\
Adrenaline & $3.66 \pm 0.06$ & $1.06 \pm 0.03$ & $19 \pm 3^{\mathrm{b}}$ \\
Cortisol & $3.61 \pm 0.06$ & $1.11 \pm 0.04$ & $39 \pm 4^{\mathrm{b}}$ \\
Neuroglycopenic symptoms & $3.16 \pm 0.06^{\mathrm{c}}$ & $1.61 \pm 0.05^{\mathrm{c}}$ & $11 \pm 1$ \\
Overall symptoms & $3.11 \pm 0.06^{\mathrm{c}}$ & $1.67 \pm 0.04^{\mathrm{c}}$ & $11 \pm 2$ \\
Autonomic symptoms & $3.05 \pm 0.06^{\mathrm{c}}$ & $1.67 \pm 0.04^{\mathrm{c}}$ & $12 \pm 1$ \\
Norepinephrine & $3.05 \pm 0.06^{\mathrm{c}}$ & & $40 \pm 3^{\mathrm{b}}$ \\
Cognitive deterioration & & $1.83 \pm 0.04$ & $\mathrm{NC}$ \\
$\quad$ 7 out of 12 tests & $2.89 \pm 0.06$ & $2.27 \pm 0.03$ & $\mathrm{NC}$ \\
$\quad$ all 12 tests & $2.45 \pm 0.06$ & & \\
\hline
\end{tabular}

${ }^{\mathrm{a}} p<0.05$ vs all parameters; ${ }^{\mathrm{b}} p<0.05$ vs growth hormone and glucagon; ${ }^{c} p<0.05$ vs all hormones. NC, Not calculated Glycaemic threshold was calculated as plasma glucose concentration at which each parameter of the subject exceeded $95 \%$ confidence limit observed in euglycaemic experiments. Lag time of response was calculated as the time it took to each parameter to change (as compared to euglycaemic experiments) since the glycaemic threshold of response had been reached. Values are mean \pm SEM

Table 4. Neuroendocrine responses to stepped hypoglycaemia, and rates of glucose infusion (GIR) needed to maintain hypoglycaemic plateaus in the male $(\mathrm{M}, n=11)$ and female $(\mathrm{F}, n=11)$ volunteers of the study

\begin{tabular}{|c|c|c|c|c|c|c|}
\hline $\begin{array}{l}\text { Plateau plasma glucose } \\
(\mathrm{mmol} / \mathrm{l})\end{array}$ & & 5 & 4.3 & 3.7 & 3 & 2.3 \\
\hline $\begin{array}{l}\text { GIR } \\
\left(\mu \mathrm{mol} \cdot \mathrm{kg}^{-1} \cdot \min \right)\end{array}$ & $\begin{array}{l}\mathrm{M} \\
\mathrm{F}\end{array}$ & $\begin{array}{l}0 \\
0\end{array}$ & $\begin{array}{l}28.7 \pm 2.8 \\
24.7 \pm 3.0^{\mathrm{a}}\end{array}$ & $\begin{array}{l}35.6 \pm 2.9 \\
29.4 \pm 2.9^{a}\end{array}$ & $\begin{array}{l}29.6 \pm 3.2 \\
23.8 \pm 2.7^{\mathrm{a}}\end{array}$ & $\begin{array}{l}20.6 \pm 3.3 \\
16.6 \pm 3.4^{\mathrm{a}}\end{array}$ \\
\hline $\begin{array}{l}\text { Glucagon } \\
(\mathrm{pg} / \mathrm{ml})\end{array}$ & $\begin{array}{l}\mathrm{M} \\
\mathrm{F}\end{array}$ & $\begin{array}{l}170 \pm 21 \\
172 \pm 25\end{array}$ & $\begin{array}{l}141 \pm 20 \\
137 \pm 18\end{array}$ & $\begin{array}{l}156 \pm 28 \\
142 \pm 19\end{array}$ & $\begin{array}{l}166 \pm 32 \\
164 \pm 25\end{array}$ & $\begin{array}{l}219 \pm 41 \\
174 \pm 23\end{array}$ \\
\hline $\begin{array}{l}\text { Adrenaline } \\
(\mathrm{nmol} / \mathrm{l})\end{array}$ & $\begin{array}{l}\text { M } \\
\text { F }\end{array}$ & $\begin{array}{l}0.35 \pm 0.04 \\
0.24 \pm 0.07^{\mathrm{a}}\end{array}$ & $\begin{array}{l}0.35 \pm 0.04 \\
0.23 \pm 0.04^{\mathrm{a}}\end{array}$ & $\begin{array}{c}0.65 \pm 0.1 \\
0.4 \pm 0.09^{\mathrm{a}}\end{array}$ & $\begin{array}{c}2.3 \pm 0.3 \\
1.79 \pm 0.3^{\mathrm{a}}\end{array}$ & $\begin{array}{l}4.81 \pm 0.6 \\
4.4 \pm 0.45^{\mathrm{a}}\end{array}$ \\
\hline $\begin{array}{l}\text { Growth hormone } \\
(\mu \mathrm{gl} / \mathrm{l})\end{array}$ & $\begin{array}{l}\mathrm{M} \\
\mathrm{F}\end{array}$ & $\begin{array}{l}2.2 \pm 1.1 \\
2.9 \pm 1.93\end{array}$ & $\begin{array}{r}1.5 \pm 1.1 \\
1.72 \pm 1.1\end{array}$ & $\begin{array}{l}1.93 \pm 0.86 \\
2.79 \pm 0.7\end{array}$ & $\begin{array}{l}25.8 \pm 4.9 \\
14.0 \pm 2.36^{a}\end{array}$ & $\begin{array}{l}43.0 \pm 7.95 \\
22.8 \pm 4.94^{\mathrm{a}}\end{array}$ \\
\hline
\end{tabular}

${ }^{\mathrm{a}} p<0.05$ females vs males

tonomic (and neuroglycopenic) symptoms in males and females was superimposable, both in terms of threshold as well as magnitude $(p=N S$, data not shown).

\section{Effect of insulin on neuroendocrine responses, symptoms and cognitive function in hypoglycaemia (high-vs low-insulin hypoglycaemia, Figures 6-8, Table 5)}

Plasma insulin and C-peptide concentrations, and glucose infusion rates (Fig. 6). In the low-insulin hypoglycaemia studies, plasma insulin concentration increased to plateau values of only $\sim 140 \mathrm{pmol} / 1$ as compared to $\sim 450 \mathrm{pmol} / \mathrm{l}$ of the high-insulin hypoglycaemia studies. Plasma C-peptide concentration was $\sim 20 \%$ less suppressed in the low-insulin hypoglycaemia studies as compared to the highinsulin hypoglycaemia studies $(0.30 \pm 0.06 \mathrm{pmol} / \mathrm{l}$ vs $0.23 \pm 0.04 \mathrm{pmol} / \mathrm{l}, p<0.05)$. The rate of glucose infusion in the low-insulin hypoglycaemia studies was lower than that of the high-insulin hypoglycaemia studies.

Plasma glucose, glucagon, adrenaline and noradrenaline (Fig. 7). Plateau plasma glucose decrements in the low- and high-insulin hypoglycaemia studies were superimposable. Plasma glucagon concentration initially was less suppressed between 60 and $90 \mathrm{~min}$ $(146 \pm 12 \mathrm{pg} / \mathrm{ml})$ in the low-insulin hypoglycaemia studies than in the high-insulin hypoglycaemia studies $(124 \pm 14 \mathrm{pg} / \mathrm{ml}, p<0.05)$. Then, plasma glucagon increased more in the low-insulin hypoglycaemia studies than in the high-insulin hypoglycaemia studies between $120-270 \mathrm{~min}(176 \pm 13 \mathrm{pg} / \mathrm{ml}$ vs $141 \pm 15 \mathrm{pg} / \mathrm{ml}$, 
Table 5. Score of autonomic, neuroglycopenic and total symptoms, and changes in cognitive function in nine subjects during identical decreases in plasma glucose concentrations induced by high low and insulin (HI-INS or LO-INS, respectively)

\begin{tabular}{lllcrr}
\hline (Min) & & 0 & 90 & \multicolumn{1}{c}{180} & 270 \\
\hline Autonomic & HI-INS & $0.1 \pm 0.02$ & $0.3 \pm 0.03$ & $0.9 \pm 0.4$ & $3.5 \pm 0.4^{\mathrm{a}}$ \\
symptom score & LO-INS & $0.1 \pm 0.01$ & $0.25 \pm 0.2$ & $1 \pm 0.3$ & $3.3 \pm 0.5^{\mathrm{a}}$ \\
Neuroglycopenic & HI-INS & $0.4 \pm 0.2$ & $1.4 \pm 0.3$ & $2.9 \pm 0.4$ & $5.5 \pm 1.1^{\mathrm{a}}$ \\
symptom score & LO-INS & $0.3 \pm 0.2$ & $1.3 \pm 0.3$ & $2.8 \pm 0.5$ & $5.9 \pm 1.0^{\mathrm{a}}$ \\
Total & HI-INS & $0.5 \pm 0.08$ & $1.6 \pm 0.1$ & $4.7 \pm 0.2$ & $9.2 \pm 0.7^{\mathrm{a}}$ \\
symptom score & LO-INS & $0.4 \pm 0.07$ & $1.5 \pm 0.3$ & $3.8 \pm 0.3$ & $9.4 \pm 0.8^{\mathrm{a}}$ \\
Cognitive function & HI-INS & $100 \pm 0$ & $99 \pm 1$ & $96.5 \pm 3$ & $93 \pm 5.4$ \\
(\% of sum of z score) & LO-INS & $100 \pm 0$ & $98 \pm 2$ & $97 \pm 3.5$ & $94 \pm 5.2$ \\
\hline
\end{tabular}

${ }^{a} p<0.05$ vs baseline

Cognitive function is expressed as percent of the sum of $z$ scores of psychomotor tests (decrease indicates deterioration). Mean $\pm \operatorname{SEM}$
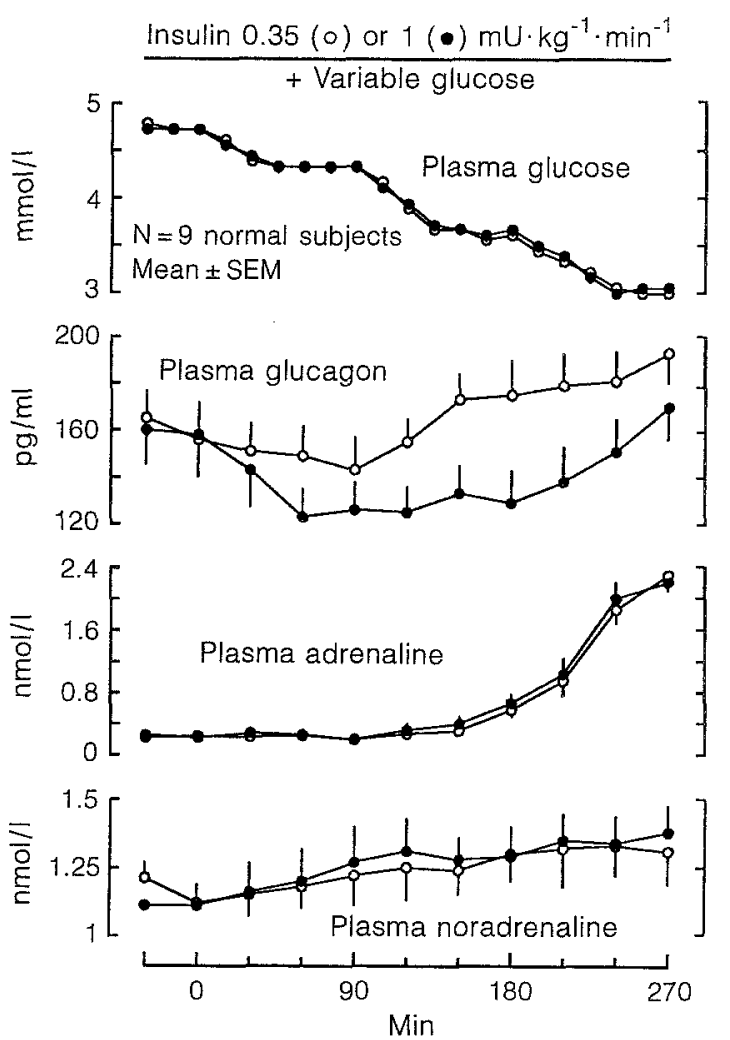

Fig. 7. Plasma glucagon, adrenaline and noradrenaline concentrations during stepped hypoglycaemia (plasma glucose, upper panel), induced by infusion of insulin at low and high rates in normal, non-diabetic subjects

$p<0.05$ ). Plasma adrenaline and noradrenaline concentrations in the low- and high-insulin hypoglycaemia studies were superimposable.

Plasma pancreatic polypeptide, growth hormone and cortisol (Fig. 8). In the low-insulin hypoglycaemia studies, plasma polypeptide concentration was initially less suppressed than in the high-insulin hypoglycaemia studies between $30-90 \mathrm{~min} \quad(20 \pm 2.4 \mathrm{pmol} / 1$ vs $14 \pm 2.9 \mathrm{pmol} / 1, p<0.05$ ); then it increased to values superimposable to those of the high-insulin hypogly-

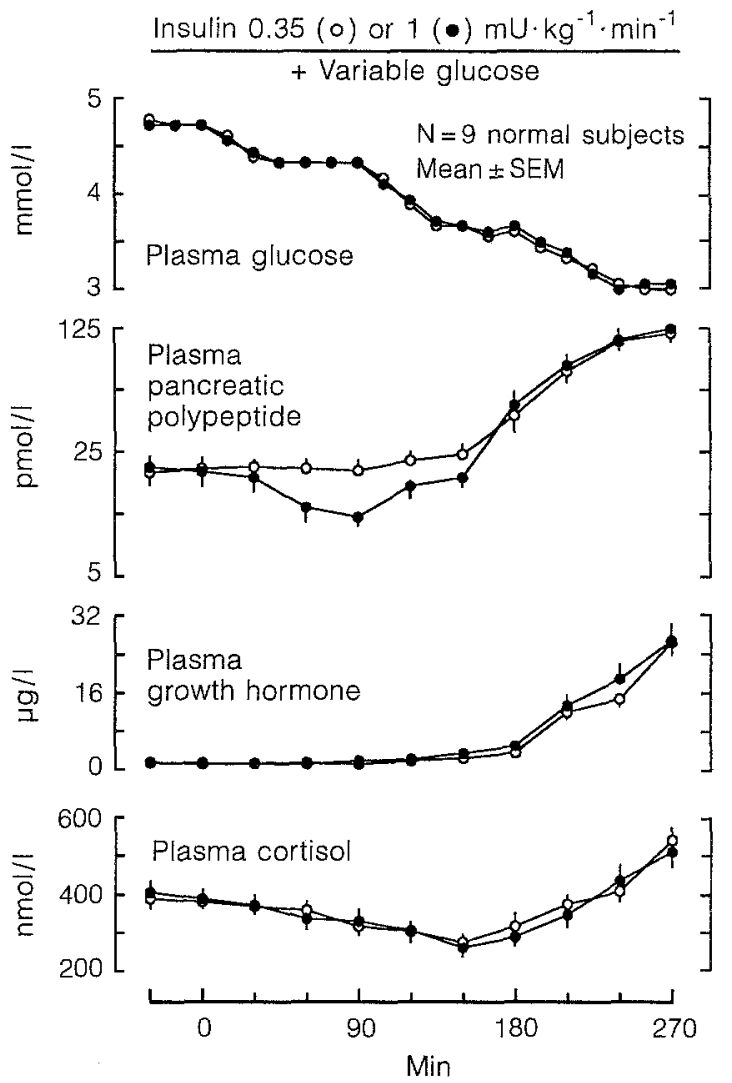

Fig.8. Plasma pancreatic polypeptide, growth hormone and cortisol concentrations during stepped hypoglycaemia (plasma glucose, upper panel), induced by infusion of insulin at low and high rates in normal, non-diabetic subjects

caemia studies. Growth hormone and cortisol responses in the low- and high-insulin hypoglycaemia studies were no different.

Autonomic, neuroglycopenic and total symptom score, and cognitive function (Table 5). There were no differences in the responses of autonomic, neuroglycopenic and total symptoms, either in the deterioration of cognitive function or during decreases in plasma glucose concentrations induced by high- and low-insulin, respectively $(p=\mathrm{NS})$. 


\section{Discussion}

The present studies confirm and extend previous reports [reviewed in 23], which indicate that, in response to progressive decrements in plasma glucose concentration, the first event is activation of the counterregulatory mechanisms; that the second, should hypoglycaemia progress, is appearance of the symptoms and, if hypoglycaemia becomes more severe, third, cognitive function deteriorates. In addition, the present studies also demonstrate several original findings.

In the present studies, the most sensitive glucoregulatory mechanism activated in defense against decrements in plasma glucose concentration was suppression of pancreatic insulin secretion which yielded a glycaemic threshold of $4.44 \pm 0.06 \mathrm{mmol} / \mathrm{l}$. Thus, a plasma glucose decrement of only $\sim 0.28 \mathrm{mmol} / 1$ below the values of the post-absorptive state was sufficient to initiate suppression of endogenous insulin secretion. Although the concept of suppression of endogenous insulin secretion during hypoglycaemia is not new at all, it is surprising that previous studies [1-6] have ignored the glycaemic threshold for suppression of insulin secretion in response to insulin-induced hypoglycaemia. The only available data are those of Cryer [23] based on the studies of Schwartz et al. [1]. Interestingly, the glycaemic threshold of suppression of plasma C-peptide reported by Cryer $(4.6 \pm 0.2 \mathrm{mmol} / \mathrm{l})$ [23] is very similar to that found in the present studies. Teleologically, the low glycaemic threshold of suppression of pancreatic insulin secretion in response to a decrement in plasma glucose, is important in limiting portal hyperinsulinaemia and favouring the rebound increase in hepatic glucose production in response to the subsequent secretion of counterregulatory hormones [24].

The present studies indicate that the parasympathetic and sympathoadrenal systems are activated at the same time during decrements in plasma glucose concentrations. This is indicated by the similar glycaemic thresholds of increase in pancreatic polypeptide $(3.83 \pm 0.06 \mathrm{mmol} / \mathrm{l})$ - a hormone which is not autonomic itself, but largely under vagal control during hypoglycaemia [25] - and adrenaline (3.66士 $0.06 \mathrm{mmol} / \mathrm{l}$ ). Regarding the classic counterregulatory hormones glucagon, adrenaline, cortisol and growth hormone [24], in the present studies all exhibited the same glycaemic threshold of response ( 3.7$3.6 \mathrm{mmol} / \mathrm{l})$. However, growth hormone and glucagon increased in plasma about 5 min earlier than adrenaline, and about $25 \mathrm{~min}$ earlier than cortisol. Regarding the glycaemic thresholds of glucagon, growth hormone and adrenaline, the results of the present studies confirm previous reports $[1,3]$. On the other hand, the glycaemic thresholds of cortisol found in the present study $(3.61 \pm 0.06 \mathrm{mmol} / \mathrm{l})$ are lower, i. e. a smaller decrease in plasma glucose is sufficient to elicit a response, as compared to previous studies $[1,3]$ using a similar methodological approach. However, such a discrepancy may be more apparent than real, because the response of cortisol is delayed due to the activation of the adrenal cortex by ACTH, a fact which may lead to an overestimation of the threshold if the glycaemic plateau is not sufficiently prolonged $[2,26]$.

A point raised by the present study regarding the increase in the counterregulatory hormones, is the lag time of response, i.e. the time it takes for a physiological response to increase after the plasma glucose concentration has reached the threshold of response. In the present studies, glucagon and growth hormone increased within approximately $15 \mathrm{~min}$ after reaching the glycaemic threshold, whereas adrenaline, and to a larger extent cortisol, increased later, approximately 19 and $40 \mathrm{~min}$, respectively, in response to the same plateau plasma glucose of approximately $3.7 \mathrm{mmol} / \mathrm{l}$. Thus, although both glucagon and adrenaline play a similar key role in a very early phase of counterregulation $[27,28]$, the fact that glucagon increases slightly earlier than adrenaline in response to hypoglycaemia, suggests that glucagon may be a more important counterregulatory hormone than adrenaline. Similarly, although both growth hormone [29] and cortisol [30] play an important role in defense against prolonged hypoglycaemia, growth hormone is probably more important than cortisol because it increases earlier.

In the present studies, the glycaemic thresholds of neuroglycopenic $(3.16 \pm 0.06 \mathrm{mmol} / \mathrm{l})$ and autonomic symptoms $(3.05 \pm 0.06 \mathrm{mmol} / \mathrm{l})$ were similar $(p=\mathrm{NS})$. This is different as compared to a previous study [3], in which the glycaemic threshold for autonomic symptoms was reported to be lower than that for neuroglycopenic symptoms. The reasons for such a discrepancy are not evident. However, our results are in agreement with the majority of previous studies [1,2], including those of Vea et al. [6]. These authors demonstrated that the glycaemic thresholds of autonomic and neuroglycopenic symptoms are identical $(\sim 3.5 \mathrm{mmol} / \mathrm{l})$ and reproducible on different days. If the glycaemic thresholds of neuroglycopenic and autonomic symptoms are identical, as the studies of Vea et al. [6] and the present studies indicate, it can be concluded that the appearance of neuroglycopenic symptoms does not indicate a more severe hypoglycaemia, as compared to that inducing autonomic symptoms, as previously suggested [3]. Thus, although less specific than the autonomic, the neuroglycopenic symptoms might be used by subjects with IDDM who have lost the autonomic symptoms, a condition referred to as hypoglycaemia unawareness [28], to alert them to impending hypoglycaemia.

The glycaemic threshold of plasma noradrenaline was greater than that of the counterregulatory hormones ( $3.05 \pm 0.06$ vs $3.65 \pm 0.06 \mathrm{mmol} / \mathrm{l}, p<0.05)$, but interestingly identical to the glycaemic threshold of the autonomic symptoms, which are induced by sym- 
pathetic activation [31]. This should not be surprising, because noradrenaline is a neurotransmitter, not a hormone [32]. However, the lag time of response of plasma noradrenaline is greater than the autonomic symptoms ( $40 \pm 3$ vs $12 \pm 1 \mathrm{~min}, p<0.05$ ), a finding which may be explained by the fact that plasma noradrenaline is only a remote indicator of the sympathetic activity [33].

In this study a battery of cognitive function tests was used to assess the effects of hypoglycaemia on cerebral function [3]. Seven out of the 12 cognitive tests deteriorated at a glycaemic threshold of $2.89 \pm 0.06 \mathrm{mmol} / \mathrm{l}$, whereas all tests deteriorated at a glycaemic threshold of $2.45 \pm 0.06 \mathrm{mmol} / \mathrm{l}$. This confirms previous findings by Mitrakou et al. [3]. On the other hand, fasting, and insulin per se did not affect cognitive function.

In the present studies, physiologic hyperinsulinaemia in the range of $150-500 \mathrm{pmol} / 1$, did not appreciably influence thresholds of responses of adrenaline, growth hormone and cortisol to hypoglycaemia, and did not affect either symptoms or deterioration of $\operatorname{cog}$ nitive function during hypoglycaemia. It was not possible in the present studies to examine the magnitude of responses because with the insulin infusion rate of $0.35 \mathrm{mU} \cdot \mathrm{kg}^{-1} \cdot \mathrm{min}^{-1}$, plasma glucose did not decrease below $3 \mathrm{mmol} / \mathrm{l}$. However, physiological hyperinsulinaemia suppressed plasma glucagon response to hypoglycaemia. Previous reports have described either a suppression [7], or an enhancement [10, 34] of adrenaline and growth hormone responses to hypoglycaemia by insulin. Kerr et al. [11] found in nine patients with IDDM of long duration, but apparently no hypoglycaemia unawareness, that supraphysiological hyperinsulinaemia $(\sim 1300 \mathrm{pmol} / 1)$ blunts the autonomic symptoms, and the counterregulatory responses of cortisol and growth hormone, whereas those of adrenaline and cognitive function were not impaired at all. It should be noted that in the study [10] in which suppressive effects of insulin on adrenaline and growth hormone was found, plasma insulin concentration was increased to supraphysiological levels ( $2600 \mathrm{pmol} / \mathrm{l})$. More recently, similar findings have been reported also when plasma insulin was increased at physiological levels [34]. In contrast, the present studies indicate that plasma glucose, not insulin concentration regulates the responses of adrenaline and growth hormone. On the other hand, the present studies point out that physiological hyperinsulinaemia suppresses glucagon in euglycaemic and hypoglycaemic conditions. Although this contrasts with a previous report of ours [35], it is in accordance with several recent reports [7-9]. The fact that insulin does not affect responses of adrenaline and growth hormone, but suppresses those of glucagon, suggests that it is unlikely that insulin impairs central recognition of hypoglycaemia [7], and indicates that insulin directly suppresses the secretion of glucagon by the pancreatic alpha cells.
In the present studies, physiological hyperinsulinaemia suppressed plasma pancreatic polypeptide concentration proportionally to hyperinsulinaemia. Although previous studies have suggested the possibility that pancreatic polypeptide is suppressed by endogenous insulin secretion in vivo [36], or modulated by hyperinsulinaemia in vitro [37], to the best of our knowledge, this is the first report clearly describing such an effect in vivo.

The present studies confirm that physiological hyperinsulinaemia activates the sympathetic nervous system, as indicated by the increase in plasma noradrenaline in the hyperinsulinaemic-euglycaemic clamp studies. This issue has recently been discussed in detail [38]. The fact that plasma noradrenaline concentration increased directly in response to hyperinsulinaemia under euglycaemic conditions, is relevant to the calculation of the glycaemic threshold of plasma noradrenaline in hypoglycaemia. In fact, the threshold could be underestimated if the hyperinsulinaemic-euglycaemic experiments were not taken into account. A qualitatively similar comment can be extended to calculations of thresholds of plasma glucagon and pancreatic polypeptide.

Finally, the present studies point out the differences in counterregulatory responses to insulin-induced hypoglycaemia in male as compared to female subjects [12-15]. The responses of glucagon, adrenaline and growth hormone, but not thresholds, were lower in females than males. On the other hand, neither thresholds nor maximal responses of symptoms were different in females as compared to males. Similarly, the responses of noradrenaline, pancreatic polypeptide and cortisol were no different, neither were the symptom scores different. These data are partly at variance with those of Widom et al. [13] who found higher thresholds for all counterregulatory hormones and symptoms in female as compared to male subjects, and those of Amiel et al. [12] who found lower adrenaline, but not glucagon responses in females as compared to males, but are largely in agreement with those of Davis et al. [15]. In the present studies, despite the fact that males and females did not differ regarding age and BMI, and despite lower counterregulatory hormone responses in females, less glucose was required in females than in males to clamp plasma glucose concentration at the same insulin-induced hypoglycaemic plateaus. This suggests that females are less insulin sensitive as compared to males, at least under hypoglycaemic conditions, as previously reported by Amiel et al. [12].

Acknowledgements. The dedicated editorial help of Ms. P. Boyce and the superb technical assistance of Giampiero Cipiciani are gratefully acknowledged. This work was supported by grant 93.00352.PF40 for C.N.R.'s finalized project aging, and by the Juvenile Diabetes Foundation grant 193108. 


\section{References}

1. Schwartz N, Clutter W, Shah S, Cryer P (1987) Glycemic thresholds for activation of glucose counterregulatory systems are higher than the thresholds for symptoms. J Clin Invest 79: 777-781

2. De Feo P, Gallai V, Mazzotta G et al. (1988) Modest decrements in plasma glucose concentration cause early impairment in cognitive function and later activation of glucose counterregulation in the absence of hypoglycemic symptoms in normal man. J Clin Invest 82: 436-444

3. Mitrakou A, Ryan C, Veneman T et al. (1991) Hierarchy of glycemic thresholds for counterregulatory hormone secretion, symptoms, and cerebral dysfunction. Am J Physiol 260:E67-E74

4. Blackman JD, Towle VL, Lewis GF, Spire J-P, Polonsky KS (1990) Hypoglycemic thresholds for cognitive dysfunction in humans. Diabetes 39: 828-835

5. Amiel SA, Simonson DC, Tamborlane WV, De Fronzo R, Sherwin RS (1987) Rate of glucose fall does not affect counterregulatory hormone responses to hypoglycemia in normal and diabetic humans. Diabetes $36: 518$ 522

6. Vea H, Jorde R, Sager G, Vaaler S, Sundsfjord J (1992) Reproducibility of glycaemic thresholds for activation of counterregulatory hormones and hypoglycaemic symptoms in healthy subjects. Diabetologia 35: 958-961

7. Diamond MP, Hallarman L, Starick-Zych K et al. (1991) Suppression of counterregulatory hormone response to hypoglycemia by insulin per se. J Clin Endocrinol Metab 72: $1388-1390$

8. Liu D, Moberg E, Kollind M et al. (1991) A high concentration of circulating insulin suppresses the glucagon response to hypoglycemia in normal man. J Clin Endocrinol Metab 73: $1123-1128$

9. Liu D, Adamson U, Lins P-E, Kollind M, Moberg E, Andréasson K (1992) Inhibitory effect of circulating insulin on glucagon secretion during hypoglycaemia in type I diabetic patients. Diabetes Care 15: 59-65

10. Davis SN, Goldstein RE, Jacobs J et al. (1993) The effects of differing insulin levels on the hormonal and metabolic response to equivalent hypoglycemia in normal humans. Diabetes 42: 263-272

11. Kerr D, Reza M, Smith N, Leatherdale BA (1991) Importance of insulin in subjective, cognitive, and hormonal responses to hypoglycemia in patients with IDDM. Diabetes 40: $1057-1062$

12. Amiel S, Maran A, Powrie JK, Umpleby AM, Macdonald IA (1993) Gender differences in counterregulation to hypoglycaemia. Diabetologia 36: 460-464

13. Widom B, Kinsley BT, Simonson DC (1991) Women and men differ in counterregulatory hormone responses to hypoglycemia. Diabetes 40 [Suppl 1]: 543 A (Abstract)

14. Diamond MP, Jones TW, Caprio S et al. (1991) Gender: a determinant of the adrenergic response to hypoglycemia. Diabetes 40 [Suppl 1]: 27 A (Abstract)

15. Davis SN, Cherrington AD, Goldstein RE, Jacobs J, Price L (1993) Effects of insulin on the counterregulatory response to equivalent hypoglycemia in normal females. Am J Physiol 265:E680-E689

16. McGuire E, Helderman J, Tobin R, Andres R, Berman M (1976) Effects of arterial versus venous sampling on analysis of glucose kinetics in man. J Appl Physiol 41: 565-573

17. Andres R, Swerdloff T, Pozefsky T, Coleman D (1966) Manual feedback technique for the control of blood glucose concentration. In: Skeggs LT Jr (ed) Automation in analytical chemistry, Mediad, New York, pp 486-491
18. DeFeo P,PerrielloG,De CosmoSet al.(1986)Comparison of glucose counterregulation during short-term and prolonged hypoglycemia in normal humans. Diabetes 35:563-569

19. Boyle P, Schwartz N, Shah S et al. (1988) Plasma glucose concentrations at the onset of hypoglycemic symptoms in patients with poorly controlled diabetes and in nondiabetics. $\mathrm{N}$ Engl I Med 318: 1487-1492

20. Fanelli C, De Feo P, Porcellati F et al. (1992) Adrenergic mechanisms contribute to the late phase of hypoglycemic glucose counterregulation in humans by stimulating lipolysis. J Clin Invest 89: 2005-2013

21. Kohn A, Annibale B, Suriano G et al. (1985) Gastric acid and pancreatic polypeptide responses to modified sham feeding: indication of an increased basal vagal tone in a subgroup of duodenal ulcer patients. Gut 26: 776-782

22. Zar J (1984) Biostatistical analysis. Prentice Hall, Englewood Cliffs

23. Cryer PE (1993) Glucose counterregulation: prevention and correction of hypoglycemia in humans. Am J Physiol 264:E149-E155

24. Bolli GB (1990) From physiology of glucose counterregulation to prevention of hypoglycaemia in type 1 diabetes mellitus. Diab Nutr Metab 3: 333-349

25. Schwartz TW (1983) Pancreatic polypetide: a hormone under vagal control. Gastroenterology 85: 1411-1425

26. Mitrakou A, Mokan M, Ryan C, Veneman T, Cryer P, Gerich J (1993) Influence of plasma glucose rate of decrease on hierarchy of responses to hypoglycemia. J Clin Endocrinol Metab 76: 462-465

27. De Feo P, Perriello G, Torlone E et al. (1991) Evidence against important catecholamine compensation for absent glucagon counterregulation. Am J Physiol 260:E203-E212

28. De Feo P, Perriello G, Torlone E et al. (1991) The contribution of adrenergic mechanisms to glucose counterregulation in humans. Am J Physiol 261:E725-E736

29. De Feo P, Perriello G, Torlone E et al. (1989) Demonstration of a role for growth hormone in glucose counterregulation. Am J Physiol 256:E835-E843

30. De Feo P, Perriello G, Torlone E et al. (1989) Contribution of cortisol to glucose counterregulation in man. Am $\mathrm{J}$ Physiol 257:E35-E42

31. Gerich J, Mokan M, Veneman T et al. (1991) Hypoglycemia unawareness. Endo Rev 12: 356-371

32. Silverberg AB, Shah SD, Haymond MW, Cryer PE (1980) Norepinephrine: hormone and neurotransmitter in man. Am J Physiol 234:E252-E256

33. Shah SD, Tse TF, Clutter WE, Cryer PE (1984) The human sympathochromoaffin system. Am J Physiol 247:E380-E384

34. Davis SN, Collins L, Price L, Hedstrom C, Shawers C (1993) The effects of physiological insulinemia on the counterregulatory response to prolonged hypoglycemia in normal man. Diabetes 42 [Suppl 1]: 44 A (Abstract)

35. Bolli G, De Feo P, Perriello G et al. (1984) Mechanisms of glucagon secretion during insulin-induced hypoglycemia in man: role of the beta-cell and arterial hyperinsulinemia. $\mathbf{J}$ Clin Invest 73: 917-922

36. Zandomegneghi R, Luciani A, Massari M et al. (1990) Interactions between endogenous and exogenous insulin and human pancreatic polypeptide secretion. Diab Metab 16: 21-25

37. Brunicardi FC, Druck P, Sun YS, Elahi D (1988) Regulation of pancreatic polypeptide secretion in the isolated perfused human pancreas. Am J Surg 155: 63-69

38. Porcellati F, Fanelli C, Bottini P et al. (1993) Mechanisms of arterial hypotension after therapeutic dose of subcutaneous insulin in diabetic subjects with and without autonomic neuropathy. Diabetes 42: 1055-1064 